\title{
Advocating for the Use of Restorative Justice Practices: Examining the Overlap between Restorative Justice and Behavior Analysis
}

\author{
Jeffrey M. Pavlacic ${ }^{1,2}$ (D) Karen Kate Kellum ${ }^{1,2} \cdot$ Stefan E. Schulenberg ${ }^{1,2}$ \\ Accepted: 13 July 2021 / Published online: 25 August 2021 \\ (C) Association for Behavior Analysis International 2021
}

\begin{abstract}
Broadly defined, restorative justice (RJ) is a set of procedures based in Indigenous peacemaking practices that reduces recidivism and guides the effective reparation of harm. RJ practices provide harm-affected parties an opportunity for engagement in the resolution process, which theoretically enhances community well-being. RJ practices overlap significantly with behavioranalytic principles. Implementing RJ practices from a context-focused, appetitive-based approach that focuses on classes of behaviors may address harmful behaviors within police organizations. RJ practices may also facilitate changes in contexts that support behaviors valued by the community. The current review discusses criminal and restorative justice, RJ processes and practices, the effectiveness of RJ in various contexts, how RJ overlaps with behavior-analytic principles and existing behavior science models in general, research suggestions, and recommendations for behavior analysts implementing RJ within police organizations and communities to address officer misconduct.
\end{abstract}

Keywords Criminal justice $\cdot$ Restorative justice $\cdot$ Behavior analysis $\cdot$ Police organizations

\section{Criminal and Restorative Justice}

Individuals convicted of crimes often serve prison or jail time (Apel \& Diller, 2017). The United States incurs incredible mass incarceration costs because of these ineffective practices (Sidman, 1989; Wagner \& Rabuy, 2017). The

This article is being published on an expedited basis, as part of a series of emergency publications designed to help practitioners of applied behavior analysis take immediate action to address police brutality and systemic racism. The journal would like to especially thank Jovonnie EsquierdoLeal for their insightful and expeditious reviews of this article. The views and strategies suggested by the articles in this series do not represent the positions of the Association for Behavior Analysis International or Springer Nature.

Guest Editor, Denisha Gingles

Jeffrey M. Pavlacic

jpavlaci@go.olemiss.edu

Karen Kate Kellum

kkellum@olemiss.edu

1 Department of Psychology, University of Mississippi, 205 Peabody Hall, MS 38677 University, USA

2 Clinical-Disaster Research Center, University of Mississippi, 203 Kinard Hall, MS 38677 University, USA disproportionate arrest (Gase et al., 2016) and incarceration (Hagle et al., 2021; Jeffers, 2019) of Black, Indigenous, and people of color (BIPOC), in addition to police misconduct, contribute to elevated incarceration rates and systemic injustices. Police misconduct has dominated society for many years (Walker, 1977) and persisted to present-day despite numerous attempts to implement internal policy changes, trainings, and accountability procedures (Rosenbaum, 2016). Instances of police misconduct against BIPOC are likely due to a combination of contextual and behavioral factors, such as racist ideologies and institutional dynamics (Hughey, 2015). Restorative justice $(\mathrm{RJ})$, a practice with peacemaking roots in different Indigenous cultures (Hand et al., 2012; Marsh, 2019; McNeill et al., 2016), has gained popularity within the context of criminal justice reform. Although RJ practices are used to address criminal justice system issues such as mass incarceration, we argue that these practices could be a small step for addressing police misconduct and brutality primarily by centralizing BIPOC voices, holding police departments and officers accountable for their behavior, and restoring and repairing affected communities. We recognize, appreciate, and support calls for the abolition of policing and systemic changes to police organizations. Given both the current context and goal of this special issue to produce actionable steps towards immediate change, we discuss the implementation of 
behavior-analytic RJ programs and the potential for these procedures to facilitate community restoration, promote healing, and modify contexts that give rise to police misconduct. Incorporation of such programs could be an intermediary step towards exhaustive changes to policing systems (see also McDowell \& Fernandez, 2018, for an overview of police abolition). The time for systemic change is long overdue.

Police misconduct is multifaceted (Son \& Rome, 2004) and includes different topographies of behavior, including but certainly not limited to substance use, brutality, excessive force (Chappell \& Piquero, 2004), and racial profiling. For purposes of deriving a definition that is useful for facilitating contextual change, we define police misconduct as any behavior committed by a police officer that negatively affects BIPOC communities and perpetuates systemic inequalities and racism. Police misconduct and criminal justice system policies disproportionately affect BIPOC. Further, relatively little progress has been made to policies and behaviors that perpetuate police misconduct (Rosenbaum, 2016). Although we know that coercion practices are largely ineffective for building repertoires (Sidman, 1989), it seems that police officers often operate in a context where coercion with different topographies is likely.

$\mathrm{RJ}$ practices may be effective and necessary for law enforcement agencies dealing with police misconduct, as officers in such organizations are often reluctant to report other officers who engage in patterns of behavior that contribute to police misconduct (Weisburd et al., 2001). As detailed throughout the current review, RJ focuses on community restoration and reparation. The larger context surrounding individual instances of misconduct determines how and whether RJ processes are implemented. For example, in cases of murder, RJ procedures can be used in conjunction with criminal justice proceedings to facilitate community restoration. First, we review traditional components of RJ, discuss common models of RJ procedures, and describe the overlap between $\mathrm{RJ}$ and behavior analysis. Then, we provide recommendations for how police departments could effectively integrate RJ practices to support behaviors valued by the community and thereby facilitate changes to contexts that give rise to police misconduct. Depending upon the specific context in which undesirable behavior occurs, addressing misconduct within police organizations using a collective leadership model such as RJ, as opposed to centralized leadership models that place the power in the hands of selected individuals (Mattaini \& Holtschneider, 2017), may be a feasible step forward to facilitate societal changes.

$\mathrm{RJ}$ suggests that the cooperative gathering of parties involved in a wrongdoing increases the probability of a successful transformation at both the community and individual level (Centre for Justice \& Reconciliation, 2008; Zehr, 2002). Howard Zehr explains that RJ processes "involve, to the extent possible, those who have a stake in a specific offense and to collectively identify and address harms, needs, and obligations, in order to heal and put things as right as possible" (Zehr, 2002, p. 37). RJ practices provide harm-affected parties an opportunity for engagement and decision making in the restitution process, which theoretically enhances community well-being without necessarily requiring forgiveness or reconciliation with the person causing harm (Centre for Justice \& Reconciliation, 2008; Zehr, 2002). RJ practices, when implemented well, provide an opportunity for reparation of harm at the community level. These practices could provide formal and sanctioned methods for communities to actively seek and respond to voices of marginalized communities and/or groups in the presence of systemic and persistent injustices. Building processes that facilitate and welcome participation from affected communities and offending police departments (the latter holding a direct responsibility for facilitating systemic change) could help address systemic policies and procedures that affect BIPOC. The Longmont Community Justice Partnership (n.d.) and Title (2011) suggest five "Rs" necessary for effective RJ processes: relationship, respect, responsibility, repair, and reintegration. These traditional elements of RJ are reviewed below, including how these facets may or may not be relevant to RJ procedures that address misconduct in police organizations.

\section{Relationship}

Crimes, including police misconduct, negatively affect individuals and their relationships with others (Zehr \& Mika, 1997). The domain of relationship implies that communities and individuals falter when wrongdoings occur (Longmont Community Justice Partnership, n.d.; Title, 2011), which is also the case for harmful police behaviors. Although RJ practices have been implemented in response to criminal acts, these various processes can also be implemented in a community setting where any societally determined problem behavior is likely to occur (n.b., a person's race and ethnicity often directly affect whether certain behaviors are considered problematic). RJ practices suggest that those affected by harmful behavior should be allowed to participate and make decisions in the restitution process, if and when those affected voluntarily decide that they are ready and willing to engage in this process (Centre for Justice \& Reconciliation, 2008). This ultimately places the resolution process in the hands of those directly involved with the initial wrongdoing (Karp, 2015; Sharpe, 1998; Zehr, 2002), while still holding those responsible accountable. Within the context of the relationship domain, one of the primary goals of RJ is to rectify broken relationships (Kuo et al., 2010; Longmont Community Justice Partnership, n.d.; Title, 2011), to the extent that the context and severity of the offense makes this possible (and with the understanding that forgiveness and reconciliation with the person causing harm do not have to occur; Zehr, 2002). RJ 
practices may be used in conjunction with the criminal justice system in cases where reintegrating the department as a whole is necessary but not the person causing harm (when such an approach is contextually appropriate for community restoration).

\section{Respect}

The second domain of traditional RJ procedures, respect, involves a safe resolution process allowing for effective communication during an RJ proceeding (Longmont Community Justice Partnership, n.d.; Title, 2011). In line with the respect domain, all parties involved in RJ processes should attempt to be respectful towards each other while acknowledging the wrongdoing that took place if they are willing to participate. This does not mean, however, that those affected should respect or accept the context and systems that give rise to harmful behaviors, or that they should forgive or reconcile with the person causing harm (Zehr, 2002). That is, the RJ process should not be seen as supporting the policies and procedures that facilitate police wrongdoing, rather the process may help communities identify and implement policies to prevent the recurrence of harmful behaviors.

\section{Responsibility}

The responsibility domain, which is perhaps the most important and relevant within the context of RJ for police misconduct, suggests that a person causing harm must be proactive in both taking responsibility for the relevant wrongdoing and developing a plan of action to right the wrong (Longmont Community Justice Partnership, n.d.; Title, 2011; Zehr \& Mika, 1997). Individuals having committed a wrongdoing choose to engage in active accountability, a process in which they are proactive in repairing harm and taking responsibility for the given wrongdoing (Karp, 2015). By choosing to be involved as part of a sentencing agreement, the person who caused harm is better able to repair damages and contribute to the revision of contexts that gave rise to the harmful behaviors (Zehr, 2002). Within a policing context, officers and departments causing harm should engage in active accountability by taking responsibility for their behavior.

\section{Repair}

The repair domain posits that an individual's behaviors should be understood within the context that gives rise to such behaviors, such as police misconduct within police organizations. By repairing the outcomes of harmful behavior, victim injuries and larger-level communities are perhaps rectified (Dekker \& Breakey, 2016), although in some cases the harmful behavior may be beyond reparable (Longmont Community Justice Partnership, n.d.; Title,
2011). Police departments with officers causing harm may choose to enact a plan to repair harm, while criminal justice policies could adjunctively sentence officers with criminal justice processes.

\section{Reintegration}

With traditional RJ proceedings, an overarching goal of RJ processes is the rekindling of relationships and trust with the perpetrator to the extent possible, as well as potential acceptance of the person causing harm back into the community (Karp, 2015; Longmont Community Justice Partnership, n.d.; Title, 2011). Reintegration of the offending officer may not always be feasible or appropriate depending upon the context in which the behavior occurs. In these cases, the focus of reintegration should be on the larger department and context with the goal of community restoration, and not necessarily the individual engaging in the harmful behavior. This reintegration process is generally overseen by $\mathrm{RJ}$ facilitators, and community and organizational leaders can also facilitate the reintegration process (Goodstein \& Aquino, 2010).

\section{Models of Restorative Justice}

In keeping with Indigenous peacemaking practices, $\mathrm{RJ}$ processes are typically face-to-face, concerned with involving all individuals affected, and mediational in nature (Bartol \& Bartol, 2019; Centre for Justice \& Reconciliation, 2008). Common but heterogeneous models of RJ implementation include victim-offender mediation (VOM), victim-offender dialogue (VOD), family/community group conferencing (FGC), boards and panels, and peacemaking/sentencing circles (see Bazemore \& Umbreit, 2001; Hass-Wisecup \& Saxon, 2018; Zehr, 2002, for thorough overviews of these models). To summarize these overviews, VOM is a mediated meeting between the victim and person who caused harm. With VOM, the mediator provides a safe and healing environment that allows (1) the person causing harm to take responsibility for said harm and (2) the development of a plan acceptable to both parties to effectively repair the harm (Bazemore \& Umbreit, 2001). Therefore, VOMs may be appropriate for less-harmful behaviors done by police that still affect marginalized groups (e.g., disproportionately targeting persons of color with routine traffic stops). VODs are similar to VOMs but may not lead to a mediated agreement between the victim and person causing harm, which may be more likely with more harmful police behaviors (e.g., physical harm or excessive use of force) that prevent full reintegration of the person causing harm back into the community. Traditional sentencing practices (e.g., prison, removal from police force, fines) for particular offenses may accompany RJ processes when appropriate for that context.

In general, FGCs are focused on the person who caused harm. Those affected can participate if needed and willing. 
However, variability exists in the implementation of FGCs. For group conferencing, a facilitator may contact the person affected and person causing harm to explain the process and solicit support parties close to each individual. Each party is given the opportunity to discuss the incident if they desire. The person causing harm hears the impact of their behaviors, whereas the victim (i.e., if willing to participate) asks questions of the person engaging in harm and plays a role in determining appropriate sanctions for the person causing harm (Bazemore \& Umbreit, 2001).

Boards and panels are an $\mathrm{RJ}$ process that both involves the community through dialogue and leads to a plan for the person causing harm to repair damages caused. The selected board may meet with the person causing harm to discuss the behavior, downstream consequences, and how this behavior has affected others (Bazemore \& Umbreit, 2001). Finally, peacemaking/sentencing circles involve larger groups with healing as the goal (Bazemore \& Umbreit, 2001; Bouffard et al., 2017). The person causing harm, those affected, and a larger group consisting of support members and community members determine a sentencing plan; this process is sometimes done collaboratively with the criminal justice system (Bazemore \& Umbreit, 2001). It is important to mention that the appropriate process should be selected on a case-by-case basis. Mediations may be more appropriate for less-severe offenses, whereas circles may be more appropriate for offenses affecting many community members or groups of individuals. As reviewed above, RJ processes can also occur simultaneously with criminal justice practices, thereby focusing on the larger department as well as the individual engaging in the harmful behavior. Adaptations to traditional RJ processes are necessary to maximize their success in addressing police misconduct, and such adaptations should be context dependent.

\section{Restorative Justice Implementation and Outcomes}

In addition to being incorporated into criminal justice procedures, RJ has become increasingly common within schools, higher education, and human resources settings (see Interim Bias Incident Response Protocol Policy, 2016; Karp, 2015; Karp et al., 2016). RJ practices have been widely implemented across different demographics and systems (Grossi \& dos Santos, 2012). This practice has also recently been used in a case of police misconduct (see Calder, 2019).

RJ practices have been shown to reduce discipline disparities for Latino children when implemented in middle schools (Schotland et al., 2016). In school systems, integrating RJ practices decreases suspensions, as do reinforcement-focused positive behavior interventions and supports programs (McNeill et al., 2016). For juvenile persons causing harm, $\mathrm{RJ}$ interventions relate to reductions in recidivism (Bergseth \& Bouffard, 2013). In offending adult samples, individuals participating in an RJ proceeding reported decreased recidivism levels compared to a control group (i.e., treatment as usual; Kennedy et al., 2018). For those who recidivated, participants in the RJ group reported less-frequent recidivism. In briefly referencing qualitative outcomes, victims of violent crimes report that they prefer to be informed about restorative processes, assuming that their participation is voluntary and the process is done in conjunction with the criminal justice system (Van Camp \& Wemmers, 2016). It is imperative to mention the heterogeneity in intensity, degree, and context of the harmful behavior and that implementing methods should be considered on a case-by-case basis using behavior-analytic principles and RJ processes (i.e., see above for a discussion of processes and potential adaptations) relevant for the specific contexts (i.e., see the sections below discussing overlap between RJ and behavior-analytic principles).

In their meta-analysis examining the efficacy of RJ programs and practices, Wilson et al. (2017) show that juvenile persons causing harm participating in one of these programs report a moderate reduction in future criminal behavior. In addition, in a meta-analysis of $\mathrm{RJ}$ programs, $\mathrm{RJ}$ was more effective than nonrestorative approaches for reducing recidivism (although these findings are limited in interpretation by a self-selection bias; Latimer et al., 2005). Sherman et al. (2015) meta-analyze 10 randomized trials and report cost-effective reductions in repeat adult and youth persons causing harm. $\mathrm{RJ}$ processes are effective in reducing repeat harm across unique samples.

\section{Restorative Justice in Policing and Other Professional Organizations}

Opie and Roberts (2017) argue for the utilization of RJ processes in response to the Black Lives Matter movement, discussing how racial discrimination is still present in the workplace setting (among numerous other settings) and could potentially be addressed through RJ processes (see also Davis, 2019, for a discussion on racial justice and RJ). Despite the evidence of the effectiveness of RJ practices, these have seldom been implemented within the context of police organizations (see Calder, 2019, for a description of one such implementation). Although, the idea of implementing RJ practices into police organizations has garnered recent attention in the media (Martin, 2021), in addition to past theoretical works (see Bazemore \& Griffiths, 2003, for an example). Police organizations, like many other organizations (Brubaker \& Zimmerman, 2009), are constantly evolving. Environmental factors that inevitably influence organizational culture and values include geographic location, era, size, history, membership composition, and challenges to administrative proceedings, among many other factors (Brubaker \& Zimmerman, 2009). There has been little behavioral research 
into effective training practices for police officers (see O'Neill et al., 2019, for an exception). Implementing behaviorally influenced RJ practices within police organizations may provide a framework to adapt to the ever-changing organizational culture, improve policing outcomes, and centralize marginalized voices.

\section{Behavioral Principles and Restorative Justice}

One potential explanation for the effectiveness of RJ could be the overlap with behavior science. An understanding of the behavior-analytic principles that unite the different processes may make it easier to implement RJ within police organizational settings. An understanding of these principles may also facilitate specific recommendations that may be disseminated within police organizations to address officer misconduct.

\section{Focus on Context}

Both RJ and behavior analysis (BA) operate on the assumptions that context influences behavior and that generating a context conducive to the behavioral goal is likely to lead to behavioral change. The context in which police officers engage in acts of misconduct must be modified. The "relationship," "repair," and "reintegration" facets of RJ suggest that persons and/or departments committing harm partake in the resolution process to create a context that repairs relationships and harm (Karp, 2015; Longmont Community Justice Partnership, n.d.; Title, 2011). RJ processes also provide community members opportunities to gain access to immediate, positive reinforcement for behaviors consistent with community engagement. RJ processes also encourage citizen/ community engagement and allow those affected to partake in the decision-making process surrounding restitution. This engagement could facilitate increased societal-level involvement in preventing harmful behavior. Some reports suggest that the Black Lives Matter movement and smartphones have already led to an observation of police brutality in the United States (e.g., Hao, 2020). RJ can create a context in which persons causing harm and community members may be even more likely to shift their perspective to be aware of contexts that create harmful behavior.

\section{Aversive Control}

Behavioral repertoires under aversive control are rigid (Wilson \& DuFrene, 2009), whereas variable behavioral repertoires are evolutionarily adaptive (Hayes et al., 2018). Aversive control produces maladaptive side effects, such as limiting learning of more acceptable behaviors, the temporary disappearance of a behavior depending on the aversive, and the pairing of aversive stimuli with other aspects of the environment (see Biglan, 2015; Dixon \& Rehfeldt, 2018; Herrnstein \& Hineline, 1966; Sidman, 1989; Sidman, 2009; Sidman \& Boren, 1957; Wilson \& DuFrene, 2009). The criminal justice system is based on the assumption that aversive control is required for behavior change, whereas BA and RJ systems do not make this assumption. Perhaps developing alternative behavioral repertoires through other programming would be more effective (e.g., PEACE POWER! strategy for schools; Mattaini, 2001), because these practices (i.e., in particular the PEACE POWER! strategy) involve constructive collaboration with police departments to facilitate systemic changes.

\section{Appetitive Context}

Production of appetitive stimuli is important for organisms (Grossen et al., 1969; Wilson \& DuFrene, 2009). Social support, an appetitive, is incredibly important within the context of psychological health (Guilaran et al., 2018). Further, "the greatest breadth of behavioral repertoires tends to occur when behavior is under the appetitive control of many sources of stimulation" (Wilson \& DuFrene, 2009, p. 40). RJ processes offer these forms of environmental enrichment. RJ processes promote the learning of new behavioral repertoires with appetitive control, such as repairing relationships (i.e., relationship) and making amends (i.e., repair). RJ processes may also lead to the development of repertoires of respect (i.e., RJ processes are not possible without being respectful during the process on the part of both the victim and the person causing harm), and reintegration (i.e., completion of various projects or restitution requirements that lead to departmental acceptance by the community in conjunction with criminal justice practices to address more harmful behaviors at the individual level).

\section{Classes of Behavior}

Response generalization occurs when a behavior generalizes to other behaviors due to reinforcement. Within the context of policing, if using excessive force is reinforced through departmental or academy trainings, using similar behaviors when on the job may become more likely (see Catania, 1998; Dixon \& Rehfeldt, 2018, for an overview of response generalization). RJ processes, as mentioned, create a context conducive to response generalization for socially acceptable behaviors. The five Rs seem to mirror a focus on the development of behavioral classes. RJ processes offer various forms of social reinforcement and create a context where response generalization is more probable. 


\section{Overcorrection}

Overcorrection, typically seen as a type of positive punishment, involves correcting environmental consequences of a given behavior and repeatedly practicing the correct form of the behavior or a positive alternative behavior (Foxx \& Azrin, 1973). The first component of overcorrection requires that the perpetrator make right the consequences of the maladaptive behavior, whereas the second component involves the repeated practicing of behavior until it is deemed adaptive (i.e., restitutional overcorrection and positive practice overcorrection; Foxx \& Azrin, 1973). RJ processes present opportunities for both of these facets of overcorrection. The person causing harm must develop a plan to right the wrong and discuss the wrongdoing (i.e., responsibility; Zehr \& Mika, 1997) through active accountability (Karp, 2015) and participate in a context where making such amends is allowed (i.e., respect and repair). Although behavioral scientists would in general label overcorrection as positive punishment, overcorrection may be a way for those causing harm to aid in the reparation of communities affected by harmful behaviors.

Although RJ research does not explicitly reference behavioral science and vice versa, there is strong overlap between both perspectives in terms of behavior-analytic principles and outcome studies. The heterogeneity in RJ processes may readily allow the incorporation of behavioral research and procedures. Kandel et al. (1976) propose a rehabilitative model of prison systems in adult persons causing harm in which they examine the use of incentive programs to promote academic achievement. Individuals participating in these programs demonstrate higher levels of academic performance. Recent empirical work evaluating the effectiveness of contingency management techniques is prevalent within the contexts of smoking (Higgins et al., 2018) and substance use in general (Petry et al., 2014), among others (see Higgins et al., 2018, for a review related to the breadth of contingency management techniques). Fixsen and Blase (2019) provide an overview of the teaching-family model, where individuals earn and lose points for appropriate and inappropriate behavior, respectively. It seems clear that exposure to an environment conducive to learning and access to reinforcers leads to behavior change.

Nietzel and Himelein (1987) discuss environmental facets and victim vulnerabilities associated with high rates of offending. They suggest implementing the following procedures to reduce offending: (1) environmental modification (i.e., target hardening of a building to make a crime more difficult) to create a context conducive to natural surveillance; (2) addressing systemic issues that place certain groups of individuals (e.g., non-whites, younger individuals, nonmarried individuals, and individuals reporting lower incomes) at a higher risk for becoming a victim; (3) raising consciousness at the societal level to increase power and resources for commonly marginalized groups; and (4) organizing citizens to come together and prevent crime. These environmental modifications afford opportunities to change future behavior of the person causing harm and community.

Third-wave behavioral therapies, such as acceptance and commitment therapy or training (ACT; Hayes et al., 1999), have some similarities to RJ processes and theory. The overarching goal of ACT is to create contexts in which people develop repertoires of behaving in ways consistent with their values (i.e., the psychological flexibility model; Hayes et al., 2006). ACT is based in relational frame theory (RFT), a theory of human language and cognition. RFT (Hayes et al., 2001) involves the human ability to derive relationships based on arbitrary stimulus properties. Adhering to a contextual or behavior framework such as ACT, cognition is considered behavior. From this perspective, it does not matter whether private or verbal behavior is "true." This perspective focuses on how the stimulus properties of such private verbal behavior serve as discriminative stimuli for escape and avoidance behaviors (Hayes et al., 1996) and prevent access to intrinsic reinforcement (i.e., values). RJ processes also do not focus on the literal content of what happened or how it happened, but how to go about influencing behavior that ultimately leads to community changes and behaviors (i.e., reductions in police misconduct) desired by the community. Of course, focusing on reintegration and community change requires some consideration of the harmful behavior, because RJ processes allow for the person engaging in the harmful behavior to take responsibility and accountability for that behavior. Within the context of ACT, reparation of harm could be considered an idiographic value at the departmental level, and RJ processes are committed action steps to take in the direction of this valued domain.

Overall, RJ processes do not typically consist of contingency management programs to reinforce adherence to an RJ process. Future researchers could evaluate the use of incentive-based programs in conjunction with traditional RJ processes to positively reinforce attendance in RJ proceedings. Researchers may also wish to evaluate the conditions under which persons causing harm and their union representatives or attorneys are most likely to choose to engage in RJ processes. RJ practices do not typically include behavioral skills training for anyone involved in the process. Behavioral researchers could assess the potential for improved RJconsistent repertoires for persons causing harm, family members, and victim participants with behavioral skills training for the process. In addition, researchers could examine the role of $\mathrm{ACT}$-consistent processes in facilitating positive RJ adoption and outcomes. One documented instance of using RJ for police misconduct has recently been met with some resistance, as the COVID-19 pandemic interfered with completion of terms (see Calder, 2020). This suggests researchers should also 
investigate mechanisms for maintaining compliance with RJ terms even during large contextual changes.

\section{Implementation Recommendations}

Behavioral sciences allow us to contribute to cultural change and promote well-being (Houmanfar et al., 2015). The overlap between RJ and behavior analysis may enable behavior analysts to help police and other community organizations to effectively use RJ practices. Communities and organizations may wish to develop an incident response committee (IRC; Interim Bias Incident Response Protocol Policy, 2016) to address police misconduct. Below, we discuss how these committees could potentially be implemented (using the Interim Bias Incident Response Protocol Policy, 2016).

The first step to implementing an IRC involves recruiting individuals from a given community. An IRC could consist of a diverse group of organizational members appointed by organizational leaders (e.g., mayors or the president of the organization). Consistent with literature referenced regarding existing outcomes of RJ, we suspect that implementing these practices may reduce undesirable behaviors in police organizations. The second component and task necessary to implementing an IRC is reporting. Those affected by harmful behaviors and community members learning of harmful behavior are encouraged to report the incident of police misconduct to the IRC using an automated form or other selfdeveloped reporting system. The third component to implementing an IRC is education, where IRC members are required to receive basic education in the domains of cultural competency, organizational/community structure, privilege, discrimination, and how to logistically address harmful behaviors as they occur in police organizations. The fourth and final component of IRC consists of coordination, where committee members meet to determine if a wrongdoing has occurred after receiving notification through the chosen reporting system. After convening, the IRC will make recommendations consistent with RJ principles to engage in a restitution process. Together, the aforementioned procedures aid in creating a context that increases the probability of behavior change, empowers those affected by harmful behaviors should they choose to participate in the process, and raises the awareness of the larger community of harmful police behaviors.

A second recommendation is to identify key personnel to become certified to facilitate RJ processes or to contract with certified professionals to develop processes by which the police organization will use RJ. These trainings are commonly held on college campuses (Acosta \& Karp, 2018). In addition, the National Association of Community and Restorative Justice (NACRJ) offers trainings to become fully certified as an RJ facilitator.
A final recommendation is that police and other organizations include members with a range of diverse views and backgrounds while exploring the development of $\mathrm{RJ}$ practices for the community. In their discussion on incorporating community members within RJ proceedings, Rossner and Bruce (2016) suggest communities should encompass a diverse range of individuals (e.g., ethnically diverse, religiously diverse). With training and education, individuals who participate in these processes may enhance the likelihood that such processes will be effective for targeting police misconduct.

In deriving a specific model example that may be beneficial to implement within a police organization based on the available data reviewed above, the most appropriate RJ model would appear to be a board, panel, or peacemaking/ sentencing circle, which is focused on community involvement. As an alternative, a hybrid of these models could be incorporated (Bazemore \& Umbreit, 2001). At first, agencies funding police departments could consider providing funding for the creation of a coalition of community members by centering voices and needs of marginalized groups, given that police "reform" sometimes consists of funding devoted to training and equipment with no apparent benefits to the community (Murakawa, 2020). Or, this process may also be placed in the hands of human services workers, such as social workers, who work within police organizations and are equipped to address nonviolent concerns. An outside party or internal party could manage reports of harmful behaviors and work with police department leaders to bridge the gap between the police and the community with the appropriate level of funding. In this way, funds could be redirected more efficiently and effectively. This proposed model is similar to an IRC described above. In terms of reporting consistent with the IRC model, the community members (i.e., at least six) could field reports of police misconduct or other undesirable behaviors using a self-designed reporting system. Members of this coalition could also receive education in domains of social sciences (i.e., the most important being cultural competency), which would allow for the effective navigation of (1) whether a wrongdoing has occurred and (2) the most feasible steps to resolving it. Committee members could then meet to determine if a wrongdoing has occurred by working with police departmental leaders. Then, using the model of a board, panel, or circle, affected parties could meet (i.e., if willing and depending on the severity of the behavior) to discuss how to most effectively repair this harm. As mentioned above, implementation of the specific process should be context dependent. If appropriate given the context, criminal justice processes may be used adjunctively with RJ processes (only if those affected are willing to participate). Criminal justice procedures could be used for the person causing harm, whereas RJ 
may involve the larger context consisting of the police department and community.

Relevant themes for discussion when considering implementing RJ practices include: (1) creating a coalition of diverse members who are interested and will be present during RJ proceedings; (2) deciding how to address incidents through automated reporting software and selection of a relevant RJ proceeding; (3) determining if harmful behavior has occurred; and (4) meeting with the person and/or department causing harm to implement the selected RJ proceeding. Professional misconduct is considered by some (Gabbioneta et al., 2019) to be an inevitable phenomenon; however, a proactive RJ system may help address police brutality.

\section{Limitations}

The heterogeneity in the contexts in which RJ processes have been applied and the processes themselves make it difficult to determine the best way to implement these practices. However, an understanding of the common behavioral processes may allow RJ to be implemented in essentially any setting. Implementing RJ committees may consume organizational or community resources. However, given the various forms of harassment commonly seen in recent instances of police brutality and within other professional organizations, systemic changes are necessary. Further, policy changes have appeared to facilitate little benefit thus far. Persons causing harm must not only participate in the process, they need to be able to take responsibility for their actions and repair their wrongdoing. If the person causing harm is not willing to engage in such dialogues and make repairs, RJ processes are futile. Contingency management and values-based programs may help to address this issue. Of course, in cases of more harmful behaviors committed by police officers, it may not be appropriate for the persons directly affected to participate given that those affected must be willing to participate (in addition to the potential for retraumatizing). Likewise, reintegration of police officers back into the community may not be practical or feasible depending on the context. Even in these contexts, larger departments from which the behavior took place may choose to participate. Many have also raised concerns about the dissemination of RJ opportunities and how those from the general public engaging in similar behaviors are not offered the opportunity to participate in RJ processes (Calder, 2019; Martin, 2021). The most prominent limitation in the current review is the broader context in which this article was written. The authors are white, Western males and females and argue for policy change in police organizations from a position of privilege, which is common in behavior analysis research and practice (Miller et al., 2019; Pritchett et al., 2020).

\section{Summary}

Police officers sometimes behave in ways that cause harm to others. RJ approaches to rectifying such harm are evidencebased, focus on both the person causing harm and the community or individuals affected, and overlap with behavioranalytic principles. RJ has been shown to be effective in multiple contexts. We suggest that using RJ approaches may be feasible for communities and police departments involved in police brutality. By modifying the physical environment to increase awareness of police misconduct at the societal level, decreasing victim vulnerability, holding those responsible for misconduct accountable, and allowing those directly affected to participate in the restitution process, we can make positive behavior changes and potentially reduce police misconduct. We are recommending that we adhere to our own, wellestablished, evidence-based principles to promote positive behavior change.

Footnote The authors recognize that we write from a perspective of privilege with little direct contact with police misconduct and other crime. We are thankful to Dr. Malika Pritchett for her willingness to spend time with us helping us more fully recognize this privilege. We also thank the special issue editors and reviewers, as well as Elijah Mudryk for constructive feedback on this work

\section{Declarations}

Conflict of Interests The authors have no conflicts of interest to disclose.

\section{References}

Acosta, D., \& Karp, D. (2018). Restorative justice as the Rx for mistreatment in academic medicine: Applications to consider for learners, faculty, and staff. Academic Medicine, 93(3), 354-356. https://doi. org/10.1097/acm.0000000000002037.

Apel, A. B., \& Diller, J. W. (2017). Prison as punishment: A behavioranalytic evaluation of incarceration. The Behavior Analyst, 40, 243 256. https://doi.org/10.1007/s40614-016-0081-6.

Bartol, C. R., \& Bartol, A. M. (2019). Introduction to forensic psychology: Research and application (5th ed.). Sage.

Bazemore, G., \& Griffiths, C. (2003). Police reform, restorative justice and restorative policing. Police Practice and Research, 4(4), 335346. https://doi.org/10.1080/15614260310001631244.

Bazemore, G., \& Umbreit, M. (2001). A comparison of four restorative conferencing models. In U.S. Department of Justice Office of Juvenile Justice and Delinquency Prevention (Ed.), OJJDP juvenile justice bulletin (pp. 1-21). U.S. Department of Justice.

Bergseth, K. J., \& Bouffard, J. A. (2013). Examining the effectiveness of a restorative rustice program for various types of juvenile offenders. International Journal of Offender Therapy and Comparative Criminology, 57(9), 1054-1075. https://doi.org/10.1177/ $0306624 X 12453551$.

Biglan, A. (2015). The nurture effect: How the science of human behavior can improve our lives and our world. New Harbinger.

Bouffard, J., Cooper, M., \& Bergseth, K. (2017). The effectiveness of various restorative justice interventions on recidivism outcomes 
among juvenile offenders. Youth Violence and Juvenile Justice, 15(4), 465-480. https://doi.org/10.1177/1541204016647428.

Brubaker, D. R., \& Zimmerman, R. H. (2009). The little book of healthy organizations: Tools for understanding and transforming your organization. Good Books.

Calder, T. (2019, October 6). Christopher Hickman's controversial plea deal and what it means for Asheville. Mountain Express. https:// mountainx.com/news/christopher-hickmans-controversial-pleadeal-and-what-it-means-for-asheville/

Calder, T. (2020, August 10). Controversial plea deal for former APD officer extended. Mountain Express. https://mountainx.com/news/ controversial-plea-deal-for-former-apd-officer-extended/

Catania, A. C. (1998). Learning (4th ed.). Prentice Hall.

Centre for Justice \& Reconciliation (2008). What is restorative justice? http://restorativejustice.org/am-site/media/what-is-restorativejustice.pdf

Chappell, A. T., \& Piquero, A. R. (2004). Applying social learning theory to police misconduct. Deviant Behavior, 25(2), 89-108. https://doi. org/10.1080/01639620490251642.

Davis, F. E. (2019). The little book of race and restorative justice: Black lives, healing, and US social transformation. Good Books.

Dekker, S. W. A., \& Breakey, H. (2016). 'Just culture:' Improving safety by achieving substantive, procedural and restorative justice. Safety Science, 85, 187-193. https://doi.org/10.1016/j.ssci.2016.01.018.

Dixon, M. R., \& Rehfeldt, R. A. (2018). Core behavioral processes. In S. C. Hayes \& S. G. Hofmann (Eds.), Process-based CBT: The science and core clinical competencies of cognitive behavioral therapy (pp. 101-117). Context Press.

Fixsen, D. L., \& Blase, K. A. (2019). The teaching-family model: The first 50 years. Perspectives on Behavior Science, 42(2), 189-211. https://doi.org/10.1007/s40614-018-0168-3.

Foxx, R. M., \& Azrin, N. H. (1973). The elimination of autistic selfstimulatory behavior by overcorrection. Applied Behavior Analysis, 6(1), 1-14. https://doi.org/10.1901/jaba.1973.6-1.

Gabbioneta, C., Faulconbridge, J., Currie, G., Dinovitzer, R., \& Muzio, D. (2019). Inserting professionals and professional organizations in studies of wrongdoing: Nature, antecedents, and consequences of professional misconduct. Human Relations, 72(11), 1707-1725. https://doi.org/10.1177/0018726718809400.

Gase, L. N., Glenn, B. A., Gomez, L. M., Kuo, T., Inkelas, M., \& Ponce, N. A. (2016). Understanding racial and ethnic disparities in arrest: The role of individual, home, school, and community characteristics. Race and Social Problems, 8(4), 296-312. https://doi.org/10. 1007/s12552-016-9183-8.

Goodstein, J., \& Aquino, K. (2010). And restorative justice for all: Redemption, forgiveness, and reintegration in organizations. Journal of Organizational Behavior, 31(4), 624-628. https://doi. org/10.1002/job.632.

Grossen, N. E., Kostansek, D. J., \& Bolles, R. C. (1969). Effects of appetitive discriminative stimuli on avoidance behavior. Journal of Experimental Psychology, 81(2), 340-343. https://doi.org/10.1037/ h0027780.

Grossi, P. K., \& dos Santos, A. M. (2012). Bullying in Brazilian schools and restorative practices. Canadian Journal of Education, 35(1), 120-136 https://doi.org/jstor.org/stable/canajeducrevucan.35.1.120.

Guilaran, J., de Terte, I., Kaniasty, K., \& Stephens, C. (2018). Psychological outcomes in disaster responders: A systematic review and meta-analysis on the effect of social support. International Journal of Disaster Risk Science, 9(3), 344-358. https://doi.org/ 10.1007/s13753-018-0184-7.

Hagle, H. N., Martin, M., Winograd, R., Merlin, J., Finnell, D. S., Bratberg, J. P., Gordon, A. J., Johnson, C., Levy, S., MacLaneBaeder, D., Northrup, R., Weinstein, Z., \& Lum, P. J. (2021). Dismantling racism against Black, Indigenous, and people of color across the substance use continuum: A position statement of the association for multidisciplinary education and research in substance use and addiction. Substance Abuse, 42(1), 5-12. https://doi.org/10. 1080/08897077.2020.1867288

Hand, C. A., Hankes, J., \& House, T. (2012). Restorative justice: The Indigenous justice system. Contemporary Justice Review, 15(4), 449-467. https://doi.org/10.1080/10282580.2012.734576.

Hao, K. (2020, June 10). How to turn filming the police into the end of police brutality. MIT Technology Review. https://www. technologyreview.com/2020/06/10/1002913/how-to-end-policebrutality-filming-witnessing-legislation/

Hass-Wisecup, A. Y., \& Saxon, C. E. (2018). Restorative Justice: Integrating theory, research, and practice. Carolina Academic Press, LLC.

Hayes, S. C., Wilson, K. G., Gifford, E. B., \& Follette, V. M. (1996). Experiential avoidance and behavioral disorders: A functional dimensional approach to diagnosis and treatment. Journal of Consulting and Clinical Psychology, 64(6), 1152-1168. https:// doi.org/10.1017/0022-006X.64.6.1152.

Hayes, S. C., Strosahl, K. D., \& Wilson, K. G. (1999). Acceptance and commitment therapy: An experiential approach to behavior change. Guilford Press.

Hayes, S. C., Barnes-Holmes, D., \& Roche, B. (Eds.). (2001). Relational frame theory: A post-Skinnerian account of human language and cognition. Kluwer Academic/Plenum.

Hayes, S. C., Luoma, J., Bond, F. W., Masuda, A., \& Lillis, J. (2006). Acceptance and commitment therapy: Model, processes, and outcomes. Behaviour Research and Therapy, 44(1), 1-25. https://doi. org/10.1016/j.brat.2005.06.006.

Hayes, S. C., Monestes, J. L., \& Wilson, D. S. (2018). Evolutionary principles for applied psychology. In S. C. Hayes \& S. G. Hofmann (Eds.), Process-based CBT: The science and core clinical competencies of cognitive behavioral therapy (pp. 179-193). Context Press.

Herrnstein, R. J., \& Hineline, P. N. (1966). Negative reinforcement as shock-frequency reduction. Journal of the Experimental Analysis of Behavior, 9(4), 421-430. https://doi.org/10.1901/jeab.1966.9-421.

Higgins, S. T., Kurti, A. N., \& Keith, D. R. (2018). Contingency management. In S. C. Hayes \& S. G. Hofmann (Eds.), Process-based CBT: The science and core clinical competencies of cognitive behavioral therapy (pp. 197-209). Context Press.

Houmanfar, R. A., Alavosius, M. P., Morford, Z. H., Herbst, S. A., \& Reimer, D. (2015). Functions of organizational leaders in cultural change: Financial and social well-being. Journal of Organizational Behavior Management, 35(1-2), 4-27. https://doi.org/10.1080/ 01608061.2015 .1035827$.

Hughey, M. W. (2015). The five I's of five-O: Racial ideologies, institutions, interests, identities, and interactions of police violence. Critical Sociology, 41(6), 857-871. https://doi.org/10.1177/ 0896920515589724.

Interim Bias Incident Response Protocol Policy. (2016, March 14). http:// www.stlcop.edu/safety/Interim\%20BIR\%20Policy.pdf

Jeffers, J. L. (2019). Justice is not blind: Disproportionate incarceration rate of people of color. Social Work in Public Health, 34(1), 113121. https://doi.org/10.1080/19371918.2018.1562404.

Kandel, H. J., Alyllon, T., \& Roberts, M. D. (1976). Rapid educational rehabilitation for prison inmates. Behaviour Research and Therapy, 14(5), 323-331. https://doi.org/10.1016/0005-7967(76)90019-X.

Karp, D. (2015). The little book of restorative sustice for colleges and universities: Repairing harm and rebuilding trust in response to student misconduct. Good Books.

Karp, D., Schackford-Bradley, J., Wilson, R., \& Williamsen, K. (2016). Campus prism: A report on promoting restorative initiatives for sexual misconduct on college campuses. https:// www.sandiego.edu/soles/documents/center-restorative-justice/ Campus_PRISM_Report_2016.pdf

Kennedy, J. L. D., Tuliao, A. P., Flower, K. N., Tibbs, J. J., \& McChargue, D. E. (2018). Long-term effectiveness of a brief 
restorative justice intervention. International Journal of Offender Therapy and Comparative Criminology, 63(1), 3-17. https://doi. org/10.1177/0306624X18779202.

Kuo, S. Y., Longmire, D., \& Cuvelier, S. J. (2010). An empirical assessment of the process of restorative justice. Journal of Criminal Justice, 38(3), 318-328. https://doi.org/10.1016/j.jcrimjus.2010.03. 006.

Latimer, J., Dowden, C., \& Muise, D. (2005). The effectiveness of restorative justice practices: A meta-analysis. The Prison Journal, 85(2), 127-144. https://doi.org/10.1177/0032885505276969.

Longmont Community Justice Partnership. (n.d.). The 5 R's of restorative practices. Longmont Community Justice Partnership. https://www. lcjp.org/5-rs

Marsh, C. (2019). Honoring the global Indigenous roots of restorative practices: Potential restorative approaches for child welfare. Center for the Study of Social Policy. https://cssp.org/2019/11/honoringthe-global-indigenous-roots-of-restorative-justice/

Martin, M. (Host). (2021). Police violence and reform: The inequality in restorative justice opportunities. National Public Radio. https:// www.npr.org/2021/04/17/988414716/police-violence-and-reformthe-inequality-in-restorative-justice-opportunities

Mattaini, M. A. (2001). Constructing cultures of non-violence: The PEACE POWER! strategy. Education and Treatment of Children, 24(4), 430-447. https://doi.org/jstor.stable/42900502.

Mattaini, M., \& Holtschneider, C. (2017). Collective leadership and circles: Not invented here. Journal of Organizational Behavior Management, 37(2), 126-141. https://doi.org/10.1080/01608061. 2017.1309334.

McDowell, M. G., \& Fernandez, L. A. (2018). 'Disband, disempower, and disarm': Amplifying the theory and practice of police abolition. Critical Criminology, 26(3), 373-391. https://doi.org/10.1007/ s10612-018-9400-4.

McNeill, K. F., Friedman, B. D., \& Chavez, C. (2016). Keep them so you can teach them: Alternatives to exclusionary discipline. International Public Health Journal, 8(2), 169-181.

Miller, K. L., Cruz, A. R., \& Ala'i-Rosales, S. (2019). Inherent tensions and possibilities: Behavior analysis and cultural responsiveness. Behavior and Social Issues, 28(1), 2-12. https://doi.org/10.1007/ s42822-019-00013-y.

Murakawa, N. (2020). Police reform works - for the police. Level. https:// level.medium.com/why-police-reform-is-actually-a-bailout-forcops-ecf2dd $7 \mathrm{~b} 8833$

Nietzel, M. T., \& Himelein, M. J. (1987). Crime prevention through social and physical environmental change. The Behavior Analyst, 10(1), 69-74. https://doi.org/10.1007/BF03392408.

O’Neill, J., O’Neill, D. A., Weed, K., Hartman, M. E., Spence, W., \& Lewinski, W. J. (2019). Police academy training, performance, and learning. Behavior Analysis in Practice, 12(2), 353-372. https://doi. org/10.1007/s40617-018-00317-2.

Opie, T., \& Roberts, L. M. (2017). Do Black lives really matter in the workplace? Restorative justice as a means to reclaim humanity. Equality, Diversity, and Inclusion: An International Journal, 36(8), 707-719. https://doi.org/10.1108/EDI-07-2017-0149.

Petry, N. M., DePhilippis, D., Rash, C. J., Drapkin, M., \& McKay, J. R. (2014). Nationwide dissemination of contingency management: The Veterans Administration initiative. American Journal of Addictions, 23(3), 205-210. https://doi.org/10.1111/j.1521-0391.2014.12092.x.

Pritchett, M., Ala'i-Rosales, S., Cruz, A. R., \& Cihon, T. M. (2021). Social justice is the spirit and aim of an applied science of human behavior: Moving from colonial to participatory research practices. Behavior Analysis in Practice, 1-19. https://doi.org/10.1007/ s40617-021-00591-7
Rosenbaum, D. P. (2016). Special issue on police integrity: An introduction. Policing: An International Journal, 39(2). https://doi.org/10. 1108/PIJPSM-03-2016-0039.

Rossner, M., \& Bruce, J. (2016). Community participation in restorative justice: Rituals, reintegration, and quasi-professionalization. Victims \& Offenders, 11(1), 107-125. https://doi.org/10.1080/15564886. 2015.1125980.

Schotland, M., MacLean, H., Junker, K., \& Phinney, J. (2016). From punitive to restorative: One school's journey to transform its culture and discipline practices to reduce disparities. In R. Skiba, K. Mediratta, \& M. Rausch (Eds.), Inequality in school discipline (pp. 225-242). Palgrave Macmillan. https://doi.org/10.1057/978-1-137$51257-413$

Sharpe, S. (1998). Restorative justice: A vision for healing and change. Edmonton, Alberta, Canada: Mediation and Restorative Justice Centre.

Sherman, L. W., Strang, H., Mayo-Wilson, E., Woods, D. J., \& Ariel, B. (2015). Are restorative justice conferences effective in reducing repeat offending? Findings from a Campbell systematic review. Journal of Quantitative Criminology, 31(1), 1-24. https://doi.org/ 10.1007/s10940-014-9222-9.

Sidman, M. (1989). Coercion and its fallout. Authors Cooperative.

Sidman, M. (2009). The measurement of behavioral development. In N. A. Krasnegor, D. B. Gray, \& T. Thompson (Eds.), Advances in behavioral pharmacology (Vol. 5, pp. 43-52). Routledge.

Sidman, M., \& Boren, J. J. (1957). A comparison of two types of warning stimulus in an avoidance situation. Journal of Comparative and Physiological Psychology, 50(3), 282-287. https://doi.org/10. 1037/h0046474.

Son, I. S., \& Rome, D. M. (2004). The prevalence and visibility of police misconduct: A survey of citizens and police officers. Police Quarterly, 7(2), 179-204. https://doi.org/10.1177/ 1098611102250705.

Title, B. B. (2011). Teaching peace: A restorative justice framework for strengthening relationships. Homestead Press.

Van Camp, T., \& Wemmers, J. A. (2016). Victims' reflections on the protective and proactive approaches to the offer of restorative justice: The importance of information. Canadian Journal of Criminology and Criminal Justice, 58(3), 415-442. https://doi.org/ 10.3138/cjccj.2015.E03.

Wagner, P., \& Rabuy, B. (2017). Following the money of mass incarceration. Prison Policy Initiative. https://www.prisonpolicy.org/ factsheets/money2017.pdf

Walker, S. (1977). A critical history of police reform: The perils of professionalism. Lexington Books.

Weisburd, D., Greenspan, R., Hamilton, E. E., Bryant, K. A., \& Williams, H. (2001). The abuse of police authority: A national study of police officers' attitudes. Police Foundation.

Wilson, D. B., Olaghere, A., \& Kimbrell, C. S. (2017). Effectiveness of restorative justice principles in juvenile justice: A meta-analysis. National Criminal Justice Reference Service. https://www.ncjrs. gov/App/AbstractDB/AbstractDBDetails.aspx?id=273052

Wilson, K. G., \& DuFrene, T. (2009). Mindfulness for two: An acceptance and commitment therapy approach to mindfulness in psychotherapy. New Harbinger.

Zehr, H. (2002). The little book of restorative justice. Good Books.

Zehr, H., \& Mika, H. (1997). Fundamental concepts of restorative justice. Center for Restorative Justice and Peacemaking, School of Social Work, University of Minnesota.

Publisher's Note Springer Nature remains neutral with regard to jurisdictional claims in published maps and institutional affiliations. 